\title{
Indice
}

\section{Prefazione - V}

\section{Parte I}

\section{Introduzione generale - 3}

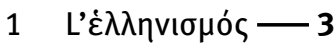

1.1 Le origini del dibattito sulla correttezza linguistica - 3

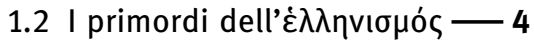

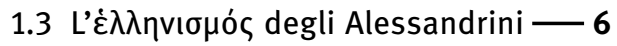

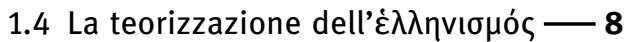

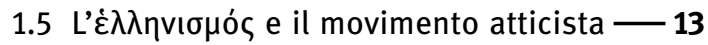

2 Barbarismo e solecismo - 15

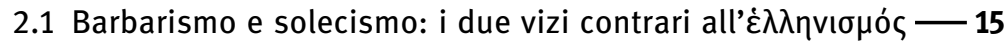

2.2 Antichità ed etimologia dei termini - 16

2.3 L'evoluzione semantica dei termini — 19

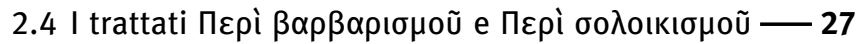

2.5 Trattazioni in altri testi $-\mathbf{3 0}$

2.6 Le tipologie di barbarismo e solecismo - 36

2.7 Solecismo e figura retorica $(\sigma x \tilde{\eta} \mu \alpha)-44$

2.8 Il solecismo "morale" -47

\section{Introduzione ai testi $-\mathbf{5 0}$}

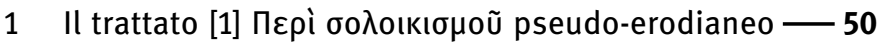

1.1 Le edizioni ottocentesche e la presente - $\mathbf{5 0}$

1.2 Datazione, attibuzione e contenuti del trattato - 53

1.3 La tradizione manoscritta -63

1.4 Conspectus siglorum -78

1.5 Stemma codicum 79

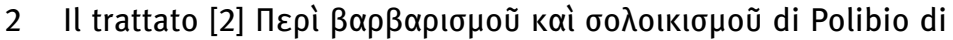
Sardi $-\mathbf{8 0}$

2.1 Datazione, paternità e fortuna $-\mathbf{8 0}$

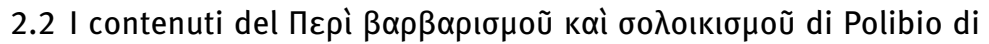
Sardi -84

2.3 La tradizione manoscritta $-\mathbf{8 6}$

2.4 Conspectus siglorum -96

2.5 Stemma codicum -97 


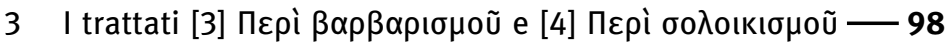

3.1 Datazione e attribuzione - 98

3.2 I contenuti -98

3.3 La tradizione manoscritta $-\mathbf{1 0 0}$

3.4 Conspectus siglorum -126

3.5 Stemma codicum 128

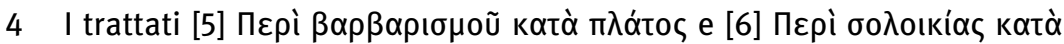

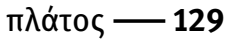

4.1 Datazione e attribuzione - 129

4.2 Struttura e contenuti -129

4.3 La tradizione manoscritta -136

4.4 Conspectus siglorum -154

4.5 Stemma codicum 156

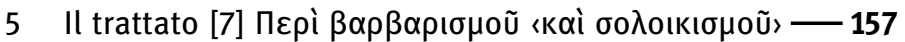

5.1 Datazione e attribuzione - 157

5.2 I contenuti -157

5.3 La tradizione manoscritta -161

5.4 Conspectus siglorum -166

5.5 Stemma codicum -167

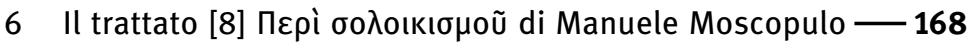

6.1 Contenuti, datazione e attribuzione del trattato -168

6.2 La tradizione manoscritta - 171

6.3 Conspectus siglorum -189

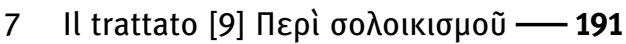

7.1 Datazione, attribuzione e contenuti del trattato - 191

7.2 La tradizione manoscritta -192

7.3 Conspectus siglorum -193

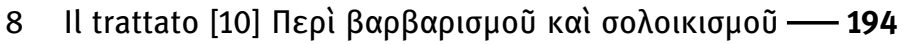

8.1 Datazione, attribuzione e contenuti del trattato - 194

8.2 La tradizione manoscritta $-\mathbf{2 0 0}$

8.3 Conspectus siglorum -203

8.4 Stemma codicum 204

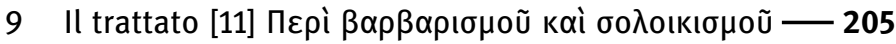

9.1 I contenuti del trattato -205

9.2 Le relazioni tra i testimoni $-\mathbf{2 0 7}$

9.3 Conspectus siglorum -207

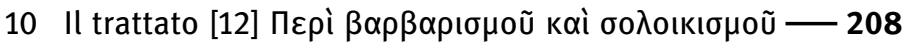
10.11 contenuti del trattato -208 


\section{Parte II}

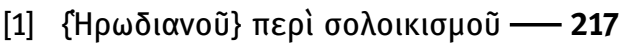

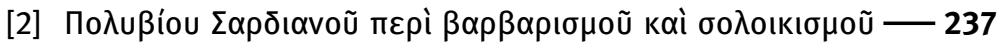

[3] Пврі $\beta \alpha \rho \beta \alpha \rho ı н о о \tilde{~ — ~} 245$

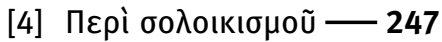

[5] Пврі̀ $\beta \alpha \rho \beta \alpha \rho ı \mu о о \tilde{~ к \alpha t \alpha ̀ ~} \pi \lambda \alpha \dot{t o \varsigma} \longrightarrow 247$

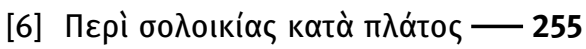

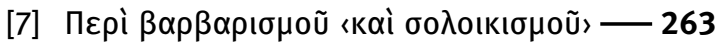

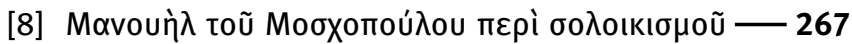

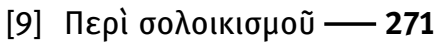

[10] Пврі̀ $\beta \alpha \rho \beta \alpha \rho ı н \mu о \tilde{~ к \alpha і ̀ ~ \sigma o \lambda о เ к ı б \mu о и ̃ ~ — ~} 271$

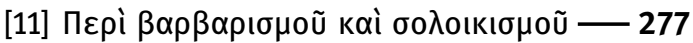

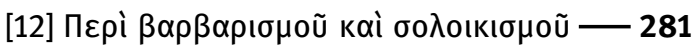

Addendum -293

Bibliografia -295

Indice dei manoscritti - 315

Indice dei loci - 319 
